\title{
Drift and deposition of pesticide applied by UAV on pineapple plants under different meteorological conditions
}

\author{
Juan Wang ${ }^{1,2}$, Yubin Lan ${ }^{1 *}$, Huihui Zhang ${ }^{3}$, Yali Zhang ${ }^{1}$, Sheng Wen ${ }^{4}$, Weixiang Yao ${ }^{1}$, \\ Jiajian Deng ${ }^{5}$ \\ (1. College of Engineering, South China Agricultural University/ National Center for International Collaboration Research on Precision \\ Agricultural Aviation Pesticides Spraying Technology (NPAAC), Guangzhou 510642, China; 2. Mechanical and Electrical Engineering \\ College, Hainan University, Haikou 570228, China; 3. USDA-Agricultural Research Service, Fort Collins, CO 80526, USA; \\ 4. Engineering Fundamental Teaching and Training Center, South China Agricultural University, Guangzhou 510642, China; \\ 5. Hainan NongFeiKe Agriculture and Technology Co. Ltd, Haikou 570100, China)
}

\begin{abstract}
Spray drift has always been a focus research area in the field of unmanned aerial vehicle (UAV) application. Under the fixed premises of UAV operating parameters, such as height, speed and spraying liquid, the droplet drift is mainly affected by meteorological conditions. In this research, the spray drift and deposition tests were conducted using a QuanFeng120 UAV in a pineapple field under various different meteorological conditions. The experimental results showed that with the changes of UAV operating height and wind speed, the start position of the in-swath deposition area changed $4 \mathrm{~m}$ in the extreme situation. The percentage of the total spray drift was from $15.42 \%$ to $55.76 \%$. The position of cumulative spray drift that accounted for $90 \%$ of the total spray drift was from $3.70 \mathrm{~m}$ to $46.50 \mathrm{~m}$ relative to the flight line. According to the downwind spray drift curve, the nonlinear equations of the same type under the four operating conditions of the UAV were fitted. The spray drift and the deposition of UAV application were significantly affected by different meteorological conditions and UAV operating heights. The results could provide a theoretical basis for UAV spraying in pineapple plants and support for spray drift control and prediction.
\end{abstract}

Keywords: UAV, spray drift, deposition, meteorological condition, pineapple DOI: $10.25165 /$ j.ijabe.20181106.4038

Citation: Wang J, Lan Y B, Zhang H H, Zhang Y L, Wen S, Yao W X, et al. Drift and deposition of pesticide applied by UAV on pineapple plants under different meteorological conditions. Int J Agric \& Biol Eng, 2018; 11(6): 5-12.

\section{Introduction}

Aerial spray has better mobility and pesticide application efficacy than ground mechanical spray ${ }^{[1-3]}$. During pesticide spraying, movement of pesticide particles or droplets toward non-target areas driven by airflow is called drift ${ }^{[4]}$. Spray drift and application safety has always been one of the key issues in the field of unmanned aerial vehicle (UAV) spraying. Droplet drift not only wastes pesticide and affects the prevention effect ${ }^{[5]}$, but also pollutes the environment ${ }^{[6-8]}$.

Any substance released into the atmosphere (spray, smoke, etc.) will be spread to other places. If spray drift loss contains high amount of active ingredient drift sedimentation in any sensitive

\section{Received date: 2018-03-12 Accepted date: 2018-10-30}

Biographies: Juan Wang, PhD candidate, research interests: precision agriculture technology and equipment, Email: 49792740@qq.com; Huihui Zhang, PhD, Research Agricultural Engineer, research interests: airborne and ground-based remote sensing, Email: huihui.zhang@ars.usda.gov; Yali Zhang, $\mathrm{PhD}$, Associate Professor, research interests: precision agricultural aviation application, Email: ylzhang@scau.edu.cn; Sheng Wen, PhD, Associate Professor, research interests: precision agricultural aviation application, Email: 58675023@qq.com; Weixiang Yao, PhD candidate, research interests: precision agriculture technology and equipment, Email: 1913835329@qq.com; Jiajian Deng, Agronomist, research interests: application of pesticides in agriculture aerial, Email: 898549910@qq.com.

*Corresponding author: Yubin Lan, PhD, Distinguished Professor, research interests: precision agricultural aviation application. National Center for International Collaboration. Research on Precision Agricultural Aviation Pesticide Spraying Technology, South China Agricultural University, Guangzhou 510642, China. Tel: +86-20-85281421, Email: ylan@scau.edu.cn. non-target area, it will cause damage to water, plant, human, animal, etc. Pesticide drift refers to a physical movement in which pesticide droplets or particles migrate from the target area to the non-target area in the air during the course of the application or after application for a period of time under uncontrolled conditions. Pesticide drift includes vapor and airborne drift, which is caused by the evaporation of the active ingredient of the pesticide. The wind drift is due to the fact that the fine droplets in the spray are carried by the airflow to the non-target area or disappearance. Dodge pointed out that due to the growing concern about environmental protection, the control of pesticide drift will drive the development of new spray technology ${ }^{[9]}$. Therefore, droplet drift has become an important issue in agricultural crop protection operation and requires attention ${ }^{[10]}$.

The physical transport of applied agrochemical sprays through the air to any off-target site is considered spray drift. Many factors affect drift including: (1) The effective composition and type of liquid preparations, droplet size and volatility; (2) Spraying equipment, use of technology, and aircraft operating parameters; (3) Meteorological conditions, such as wind speed and direction, temperature and humidity, atmospheric stability and terrain; (4) The operator's sense of responsibility and skill level ${ }^{[11-14]}$. To control weeds, pests and diseases, it needs optimal pesticide dose, the most suitable droplet size, and weather conditions, so that the droplets in the target surface can be better coverage, attachment, spread and absorption. Under the control of the same dosage, the smaller the particle size, the better the coverage, however, there is a risk of drift. Under the condition that the parameters of the UAV are relatively stable, the influence of meteorological conditions on 
the deposition and spray drift of liquid pesticide is particularly important. Applicators must understand weather conditions when spraying pesticides, such as: wind speed, wind direction, temperature, humidity and other effects of weather conditions ${ }^{[15]}$. One of the meteorological conditions that can occur to spray drift is wind speed. At higher wind speeds, droplets dispersion and dilution increase, ground deposition concentration decreases, and the wind must blow the droplets or enough active ingredients in the particles to the non-target area. The droplets cannot be obstructed by obstructions or vegetation between the spray zone and the non-target area. The droplet deposition behavior and drift characteristics are the basic aspects of the spray effect ${ }^{[16,17]}$. According to the Chinese Civil Aviation Industry Standards, measuring droplet drift materials are usually polyethylene wire, glass, filter paper, water sensitive paper, chromatography and other methods. Many domestic and foreign experts and scholars researched on aerial spraying operation efficacy ${ }^{[18-21]}$. Some used water sensitive paper and mylar card to analyze the deposition parameters. Hoffmann and Hewitt concluded that although USDA-ARS system, Swath Kitcamera-based system and Droplet Scan scanner-based system have different test methods, the test results were similar ${ }^{[22]}$ Franz applied fluorescence spectrophotometers and light-sensitive paper on cotton leaves to examine the effects of canopy characteristics and climatic conditions on the deposition and drift of cotton droplets ${ }^{[23]}$. Lan et al. ${ }^{[24]}$ added adjuvants in the fixed-wing aircraft on the spraying of cotton, and the effects of different adjuvants on the spray drift were studied. Xue et $\mathrm{al}^{[25]}$. tested the spray and deposition of UAV in a rice field under the condition of Z-3 UAV operating parameters which could control $90 \%$ of the drift in $8 \mathrm{~m}$. Fritz suggested that the influence of wind speed in different meteorological conditions is the most important. He also indicated that wind speed was the dominant factor affecting the transport and fate of aerially applied sprays ${ }^{[26]}$.

China is the world's fourth largest producer of pineapple. Due to Hainan Island's inherent advantages of natural environment, pineapple production accounts for about $26 \%$ of the total in the country. Pineapple is the third largest fruit in Hainan Island, only below the production of banana and mango ${ }^{[27]}$. A survey found that the main factors that harm Hainan pineapple production are pests, diseases, fertilizer damage and phytotoxicity. Pests and diseases include pineapple wilt disease, leaf spot, heart rot and pineapple mealybug. Heart rot disease causes damage to new plantation pineapple seedlings, wilt and leaf spot disease is mainly harmful to pineapple plants covered with fruit, and pineapple mealybug mainly damages pineapple plant in orchard. At present, aerial spray test applied in pineapple plants has not been reported. Because Hainan Island belongs to the tropical monsoon climate, the weather conditions are particularly important when a UAV is used for pesticide application. At present, the domestic research on the application of agricultural UAV has mainly focused on the effects of operation parameters of aerial spraying on the characteristics of droplet deposition distribution ${ }^{[28]}$. These main parameters including air temperature, humidity, wind speed and direction and UAV operating height, are all needed to be tested and evaluated.

At present, technical articles about aerial deposition and spray drift on pineapple plants by a UAV has not been reported in China, the experimental results can provide data and theoretical support for the spraying of pineapples under different meteorological conditions. Due to the lack of information on spray and deposition of UAV application in pineapple pants, this article was mainly to test the drift and deposition law of single-rotor oil-based UAV in the different meteorological conditions in a pineapple field. Test results can provide data support and theoretical basis for pineapple spraying drift control and selection of suitable UAV operation parameters.

\section{Materials and methods}

\subsection{Test plan and meteorological conditions}

The test place is located in, a $5 \mathrm{hm}^{2}$ pineapple orchard in Bolian town, Lingao County, Hainan Province (19 52'13"N, $\left.109^{\circ} 38^{\prime} 39^{\prime \prime}\right)$, China. Test meteorological data were recorded, in January 2-5, 2017 using a Kestrel Meterograph (Model NK-5500, Nielsen-Kellerman Co., Boothwyn, PA, USA). The Meterograph was placed in the upwind $5 \mathrm{~m}$ away from the flight line. The distance from the ground was $105 \mathrm{~cm}$, and data acquisition time interval was $5 \mathrm{~s}$. The meteorological data processing segment was performed concurrently when UAV began to spray. The data were averaged in $30 \mathrm{~s}$ for mylar cards deposition and in $60 \mathrm{~s}$ for monofilament of drift testing devices. The wind direction refers to the angle with the direction of the north (the direction north to $0^{\circ}$, east to $90^{\circ}$, south to $180^{\circ}$, and west to $270^{\circ}$ ). The direction of the flight was from north to south. In this paper, QF120 represents QuanFeng120 UAV (Anyang QuanFeng Aviation Plant Protection Technology Co., Ltd, Henan, China). Figure 1 shows a 3D visualization. Sampling locations are shown in Figure 2. The two sample lines with a distance of $40 \mathrm{~m}$, were perpendicular to the UAV flight line, and the sample line length was $60 \mathrm{~m}$. According to the spray characteristic of UAV, the in-swath deposition area was preset to $8 \mathrm{~m}$. Sampling stations were placed parallel to the prevailing wind. There were two sampling lines (Line 1 and Line 2) for each replication. For each sampling line, in-swath deposition samplers were directly under the UAV and were located at $10 \mathrm{~m}, 8 \mathrm{~m}, 6 \mathrm{~m}, 4 \mathrm{~m}, 3 \mathrm{~m}, 2 \mathrm{~m}, 1 \mathrm{~m}$, and $0 \mathrm{~m}$ upwind from the downwind edge of the spray swath (designated as $-10 \mathrm{~m},-8 \mathrm{~m}$, $-6 \mathrm{~m},-4 \mathrm{~m},-3 \mathrm{~m},-2 \mathrm{~m},-1 \mathrm{~m}$, and $0 \mathrm{~m}$ ). At each location, a mylar card was placed. Downwind deposition samples were placed at $1 \mathrm{~m}, 2 \mathrm{~m}, 3 \mathrm{~m}, 4 \mathrm{~m}, 6 \mathrm{~m}, 8 \mathrm{~m}, 10 \mathrm{~m}, 20 \mathrm{~m}, 30 \mathrm{~m}, 40 \mathrm{~m}$, and $50 \mathrm{~m}$ downwind from the edge of the spray swath. mylar card size was $10 \mathrm{~cm} \times 8 \mathrm{~cm}$. Nineteen sampling points were placed for each sampling line. mylar card was located in the distance of 70 $\mathrm{cm}$ from the ground, and the average canopy height of pineapple plants was $88 \mathrm{~cm}$. Parallel to the flight line, 3 drift testing devices were arranged in the middle of the two sample lines. The distance of three devices from the flight line was $10 \mathrm{~m}, 25 \mathrm{~m}$, and $50 \mathrm{~m}$, respectively. Each drift testing device consisted of two retractable stainless steel tubes and three monofilament line $(\varnothing=0.45 \mathrm{~mm})$. The height of the three monofilament lines was $1 \mathrm{~m}, 2 \mathrm{~m}$, and $5 \mathrm{~m}$, respectively. Table 1 shows the parameters of the UAV and crop characteristics. Figure 3 shows the UAV flight track collected by Beidou system (an aerial Beidou positioning UB351 system developed by the South China Agricultural University with the RTB differential positioning function was equipped) ${ }^{[29]}$.

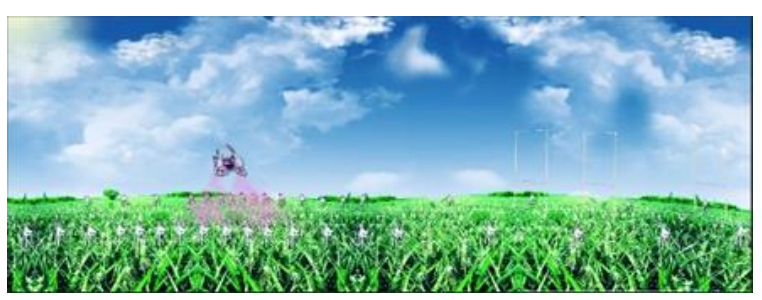

Figure 1 UAV spray drift test collection and sampling location $3 \mathrm{D}$ visualization 


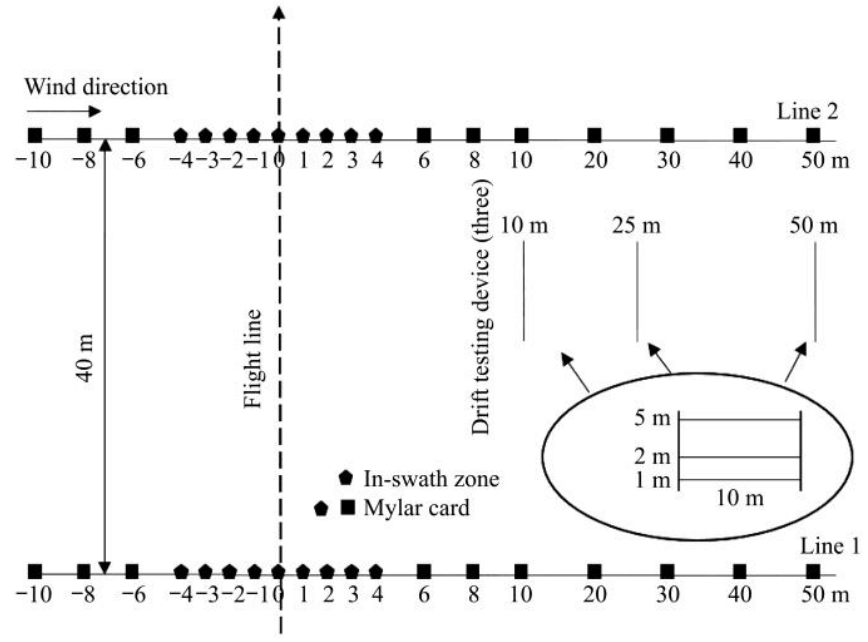

Figure 2 Test site layout showing flight line and sample locations

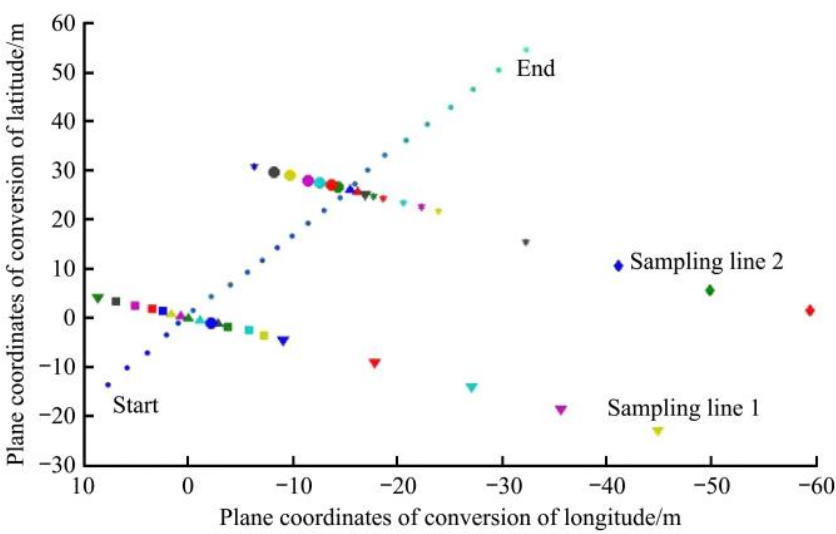

Figure 3 UAV flight track by Beidou and monofilament line samples

Table 1 UAV specific parameters and crop characteristics.

\begin{tabular}{lc}
\hline \multicolumn{1}{c}{ QuanFeng120 } & Parameters \\
\hline Power type & oil driving single rotor \\
Nozzle Type & $120-02$ \\
Droplet size $/ \mu \mathrm{m}$ & 268.6 \\
Machine size $/ \mathrm{mm}$ & $2130 \times 700 \times 670$ \\
Flow rate $($ single $) / \mathrm{mL} \cdot \mathrm{min}^{-1}$ & 800 \\
Number of nozzles & 2 \\
Tank capacity $/ \mathrm{L}$ & 12 \\
Spray swath $/ \mathrm{m}$ & $5-8$ \\
Flight endurance $/ \mathrm{min}^{-1}$ & $\geq 25$ \\
Driving speed $/ \mathrm{km} \cdot \mathrm{h}^{-1}$ & 10.8 \\
Crop density $/ \mathrm{hm}{ }^{-2}$ & 22500 \\
Crop type & pineapple fruit tree \\
The average height of the crop $/ \mathrm{cm}$ & 88 \\
\hline
\end{tabular}

\subsection{Spraying method and pesticide type}

In accordance with the design of test plan, place of mylar card, assembly drift testing device and monofilament line, UAV debugging was completed, equipped with Beidou system to capture the UAV flight trajectory. The spraying pesticide was composed of water, dinotefuran (Mitsui Chemicals AGRO Inc., Tokyo, Japan) and rhodamine B (Sigma-Aldrich Inc., USA.) tracer. The concentration of dinotefuran and rhodamine $\mathrm{B}$ tracer were $10 \mathrm{~g} / \mathrm{L}$ and $2 \mathrm{~g} / \mathrm{L}$, respectively. Each UAV operation was completed when the sampling devices were completely dry. Disposable gloves were worn to collect samples. mylar cards were sealed with labeled plastic bag. Monofilament lines were rolled on a plastic hollow shaft using a dedicated collection device and placed in labeled plastic bag. All samples were numbered in order and put into an ice box and brought back to the laboratory (China Tropical Agricultural Sciences Institute Test Center) for analysis. mylar cards and monofilament lines were eluted with $20 \mathrm{~mL}$ of ultrapure water and the elution water was placed in a cuvette to measure the fluorescence, and calculate the concentration of rhodamine $\mathrm{B}$ contained in the sample Using the molecular fluorescence spectrophotometer instrument (Model-F7000, HITACHI Inc., Tokyo, Japan). The fluorescence concentration curve was fitted with the liquid sample, and the correlation was $99.9 \%$. After the sample concentration value is obtained, the deposition amount of the sample was calculated according to Equations (1) and (2) as the percentage of sample deposition rate:

$$
\begin{gathered}
\beta_{d e p}=\frac{\left(\rho_{\text {smpl }}-\rho_{b l k}\right) \cdot F_{c a l} \cdot V_{d i i}}{\rho_{\text {spray }} \cdot A_{c o l}} \\
\beta_{\text {dep } \%}=\frac{\rho_{\text {dep }} \times 10000}{\beta_{v}}
\end{gathered}
$$

where, $\beta_{d e p}$ is the spray drift deposit, $\mu \mathrm{L} / \mathrm{cm}^{2} ; \rho_{\text {smpl }}$ is the fluorimeter reading of the sample; $\rho_{b l k}$ is the fluorimeter reading of the blanks (collector+ ultrapure water); $F_{\text {cal }}$ is the calibration factor; $V_{d i i}$ is the volume of ultrapure water used to dilute tracer from collector, $\mathrm{L} ; \rho_{\text {spray }}$ is the spray concentration, or amount of tracer solute in the spray liquid sampled at the nozzle, g/L; $A_{c o l}$ is the projected area of the collector for catching the spray drift, $\mathrm{cm}^{2}$; $\beta_{d e p \%}$ is the spray drift percentage, $\% ; \beta_{v}$ is the spray volume, $\mathrm{L} / \mathrm{hm}^{2}$.

\section{Results and discussion}

3.1 Samples $-10 \mathrm{~m}$ to $50 \mathrm{~m}$ from in-swath and downwind edge of swath-mylar tests under different meteorological conditions

UAV driving speed was kept at a fixed value of $3 \mathrm{~m} / \mathrm{s}$. Although the environment was complex and changeable, the temperature fluctuation value was within $(26 \pm 2)^{\circ} \mathrm{C}$ and relative humidity floats in $(50 \pm 15) \%$. UAV operation parameters, meteorological conditions, and simplified flight number abbreviations (a and $\mathbf{f}$ curves) are shown in Table 2. UAV operating height refers to the pineapple canopy.

Figure $4 \mathrm{a}$ shows the distribution curves of the mylar cards in the sampling areas. It can be seen from Figure 4, when the QF120 was operated at the height of $2.5 \mathrm{~m}$, the maximum deposition of a-curve and b-curve occurred at $1 \mathrm{~m}$ and $-1 \mathrm{~m}$ position. The in-swath deposition area of b-curve moves backwards $2 \mathrm{~m}$ of the a-curve. After $6 \mathrm{~m}$ and $4 \mathrm{~m}$, respectively, spray drift in a-curve and $\mathbf{b}$-curve drastically reduced. Both of them had spray drift on the upwind. As it can be seen from Figure 4b, when the QF120 operation height was $1.5 \mathrm{~m}$, the $\mathbf{d}$-curve with higher wind speed had similar in-swath deposition area to the c-curve with low wind speed. After $8 \mathrm{~m}$ and $6 \mathrm{~m}$, respectively, spray drift in c-curve and d-curve decreased sharply. Figure $4 \mathrm{c}$ shows that when the operating height was $3.5 \mathrm{~m}$, the e-curve of the higher wind speed was significantly move backwards the in-swath deposition area of f-curve, and the maximum deposition amount of the two was at $-1 \mathrm{~m}$ and $3 \mathrm{~m}$, respectively. The amount of upwind deposition was close to 0 . The drift decreased after $20 \mathrm{~m}$ in e-curve and $3 \mathrm{~m}$ in f-curve. The results verify the conclusion of Bird et al. ${ }^{[30]}$ And further stated that given similar stability conditions, increasing wind speeds will tend to increase off-target deposition. Figure 5 shows the percentage of a-f curves in-swath deposition spray 
accounts for the total amount. The deposition bar of a-f curves that under $1.5 \mathrm{~m}$ (c and $\mathbf{d}$ curves) and $2.5 \mathrm{~m}$ (a and $\mathbf{b}$ curves) operation height, the wind speed effect on the deposition rate to the total amount of spraying was less than $5 \%$, but the in-swath deposition decreased $22 \%$ by the wind speed varying by $1 \mathrm{~m} / \mathrm{s}$ at the height of $3.5 \mathrm{~m}$ ( $\mathbf{e}$ and $\mathbf{f}$ curves).

Table 2 Meteorological conditions and operating parameters

\begin{tabular}{|c|c|c|c|c|c|c|}
\hline Parameters & a-curve & b-curve & c-curve & d-curve & e-curve & f-curve \\
\hline Real time wind speed $/ \mathrm{m} \cdot \mathrm{s}^{-1}$ & 4.7 & 1.8 & 0.7 & 2.2 & 3.7 & 1.78 \\
\hline Mean speed $/ \mathrm{m} \cdot \mathrm{s}^{-1}(30 \mathrm{~s})$ & 3.18 & 2.17 & 1.17 & 1.37 & 3.93 & 1.71 \\
\hline Mean speed $/ \mathrm{m} \cdot \mathrm{s}^{-1}(60 \mathrm{~s})$ & 2.82 & 2.0 & 1.14 & 1.25 & 3.59 & 2.02 \\
\hline $\mathrm{SD} / \mathrm{m} \cdot \mathrm{s}^{-1}(60 \mathrm{~s})$ & 0.76 & 0.60 & 0.49 & 0.60 & 0.73 & 0.46 \\
\hline $\mathrm{CV} / \%(60 \mathrm{~s})$ & 27 & 29 & 43 & 48 & 20 & 23 \\
\hline Mean wind direction $/\left(^{\circ}\right)(30 \mathrm{~s})$ & 69.7 & 92.5 & 169 & 128 & 65.5 & 63 \\
\hline UAV operating height $/ \mathrm{m}$ & 2.5 & 2.5 & 1.5 & 1.5 & 3.5 & 3.5 \\
\hline UAV driving speed $/ \mathrm{m} \cdot \mathrm{s}^{-1}$ & 3 & 3 & 3 & 3 & 3 & 3 \\
\hline Mean temperature $/{ }^{\circ} \mathrm{C}(30 \mathrm{~s})$ & 27.2 & 26.1 & 27.8 & 25.9 & 24.9 & 26.5 \\
\hline Mean relative humidity $/ \%$ (30 s) & 50.8 & 60.55 & 60.8 & 57.6 & 67.6 & 57.6 \\
\hline
\end{tabular}

Note: SD- standard deviation, CV- coefficient of variation.

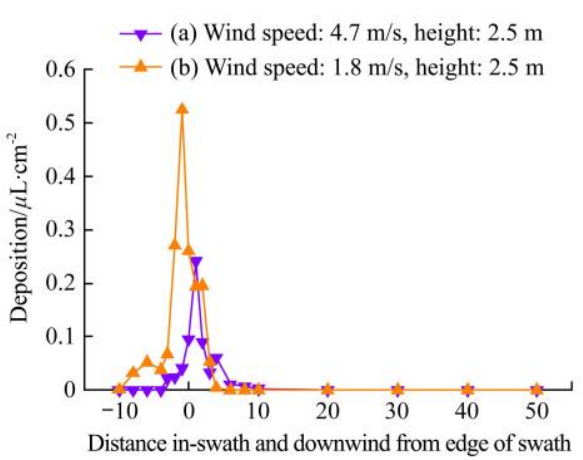

a. $\mathbf{a}$ and $\mathbf{b}$ curves
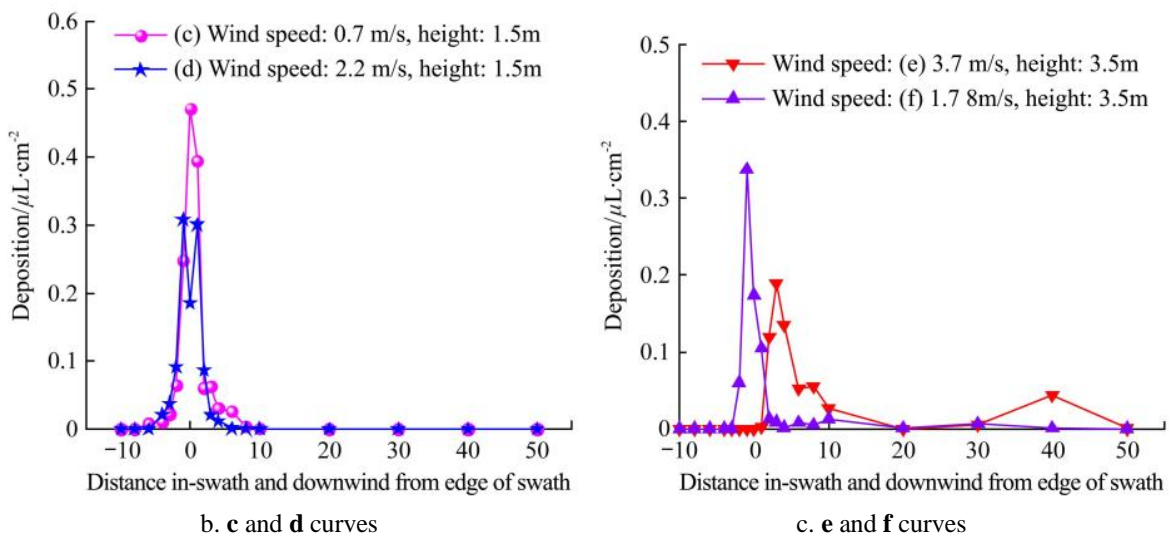

Figure 4 a-f curves in-swath and downwind from edge of swath deposit as measured on horizontal mylar cards

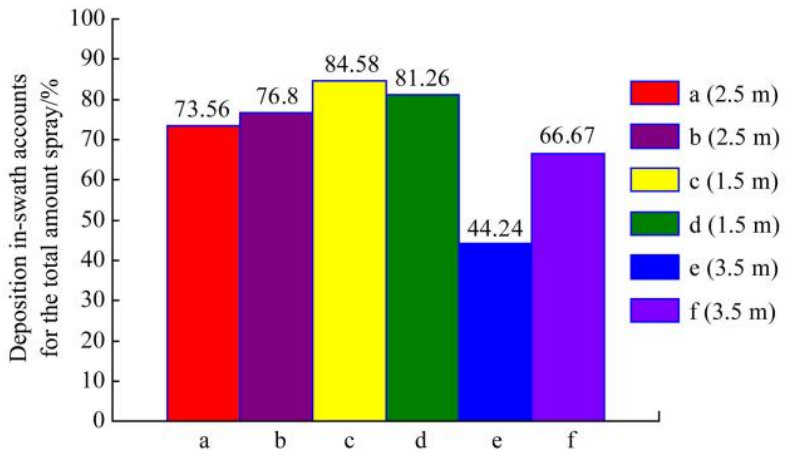

Figure 5 a-f curves deposition in-swath account for the total amount of spray (\%) as measured on horizontal mylar cards

\subsection{Samples from downwind edge of mylar card tests under different meteorological conditions}

Figures 6 and 7 show a and $\mathbf{b}$ curves in the downwind of spray drift percentage and the cumulative drift percentage of total measured drift at each sampling point. At the operating height of $2.5 \mathrm{~m}$, real time wind speeds were $4.7 \mathrm{~m} / \mathrm{s}$ and $1.8 \mathrm{~m} / \mathrm{s}$, and wind direction difference was $37^{\circ}$. The a-curve shows that the cumulative drift percentage of $90 \%$ of total measured drift occurred at about $10.05 \mathrm{~m}$, and the spray drift percentage at the $10 \mathrm{~m}$ position was $1.52 \%$. The a-curve total spray drift accounted for $26.44 \%$ of the total spraying. The b-curve shows that the cumulative drift percentage of $90 \%$ of total measured drift occurred at about $3.70 \mathrm{~m}$, and the spray drift percentage at the $4 \mathrm{~m}$ position was $2.22 \%$. After $6 \mathrm{~m}$, the drift was nearly zero. The b-curve total spray drift accounted for $23.20 \%$ of the total spraying. The average wind speed of a-curve and $\mathbf{b}$-curve in $30 \mathrm{~s}$ were $3.18 \mathrm{~m} / \mathrm{s}$ and $2.17 \mathrm{~m} / \mathrm{s}$, respectively. The change of wind speed at $(-3 \mathrm{~m}$ to $3 \mathrm{~m}$ ) had significant effect on the deposition of a-curve and $\mathbf{b}$-curve $(p<0.05)$. a-curve $\left(R^{2}=0.995, p<0.001\right)$ and b-curve $\left(R^{2}=0.996\right.$, $p<0.0001)$ were obtained by a nonlinear fitting. The fitting curves of the drift deposit and the downwind distance were obtained as shown in Equation (3) and the fitting parameters are shown in Table 3 .

$$
y=Y_{0}+\frac{A}{\sqrt{2 \pi} \cdot w \cdot x} \cdot \exp \left(-\frac{\left(\ln \left(x / x_{c}\right)\right)^{2}}{2 w^{2}}\right)
$$

where, $y$ is the drift deposit; $x$ is the downwind distance; $Y_{0}, A, w$, $x_{c}$ are all coefficients.

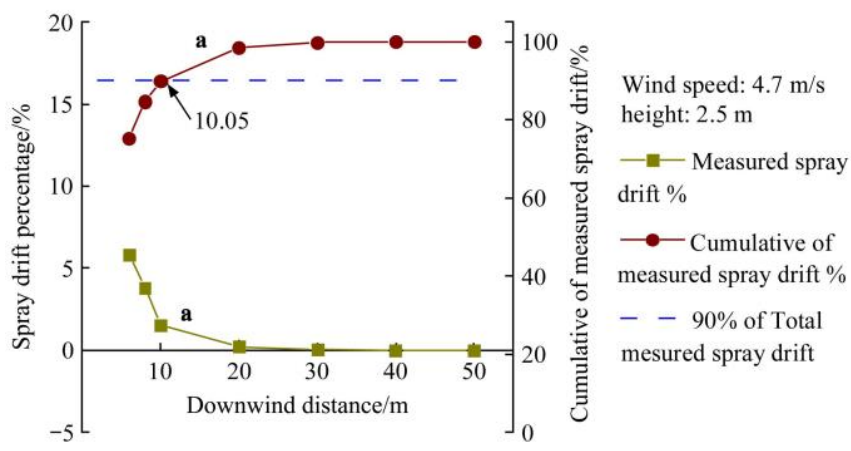

Figure 6 a-curve in-swath and downwind from edge of swath deposit as measured on horizontal mylar cards 


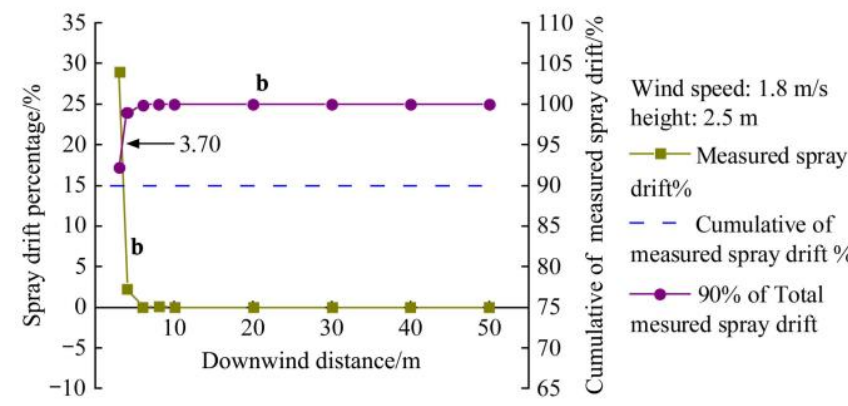

Figure 7 b-curve in-swath and downwind from edge of swath deposit as measured on horizontal mylar cards

Table 3 a and b curves drift nonlinear fitting curve coefficients

\begin{tabular}{ccccc}
\hline & $Y_{0}$ & $A$ & $w$ & $X c$ \\
\hline c & 0.000089037 & 0.05867 & 0.3605 & 6.38598 \\
b & $3.31313 \mathrm{E}-5$ & 0.00797 & 0.1787 & 3.67159 \\
\hline
\end{tabular}

Figures 8 and 9 show $\mathbf{c}$ and $\mathbf{d}$-curves in the downwind of spray drift percentage and the cumulative drift percentage of total measured drift at each sampling point. At the UAV operating height of $1.5 \mathrm{~m}$, real-time wind speed were $0.7 \mathrm{~m} / \mathrm{s}$ and $2.2 \mathrm{~m} / \mathrm{s}$, and wind direction difference was $40^{\circ}$. The c curve shows that the cumulative drift percentage of $90 \%$ total measured drift occurred at about $6.90 \mathrm{~m}$, and the spray drift percentage in c-curve at the $6 \mathrm{~m}$ and $8 \mathrm{~m}$ were $14.43 \%$ and $1.87 \%$, respectively. After $10 \mathrm{~m}$, it was nearly zero. The c-curve total spray drift accounted for $15.42 \%$ of the total spraying. The d-curve shows that the cumulative drift percentage of $90 \%$ total measured drift occurred at about $3.91 \mathrm{~m}$. The spray drift percentage in d-curve at the $4 \mathrm{~m}$ position was 5.328\%. After $6 \mathrm{~m}$ position, drift was nearly zero. The total amount of drift accounted for $18.74 \%$ of the total amount of spraying. Since the wind direction in $\mathbf{c}$ and $\mathbf{d}$-curves changed from $160^{\circ}$ to $120^{\circ}$, the d-curve cumulative drift percentage of $90 \%$ of the total measured drift position moved forward $3 \mathrm{~m}$ than c-curve, but the d-curve total amount drift was still slightly higher than the c-curve. Both of $\mathbf{c}$ and $\mathbf{d}$ curves had drift at $-3 \mathrm{~m},-4 \mathrm{~m}$, and $-6 \mathrm{~m}$ position in the upwind. The upwind cumulative drift percentage in c-curve and d-curve accounts for $38.38 \%$ and $56.20 \%$ of the total drift. The change of wind speed at the whole sample line had no significant effect on the deposition of c-curve and d-curve $(p<0.66)$. c-curve $\left(R^{2}=0.999, p<0.0001\right)$ and d-curve $\left(R^{2}=0.997, p<0.0001\right)$ were obtained by a nonlinear fitting. The fitting curves of the drift deposit and the downwind distance were obtained as shown in Equation (4) and the fitting parameters are shown in Table 4.

$$
y=Y_{0}+\frac{A}{\sqrt{\pi} \cdot w \cdot x} \cdot \exp \left(-\frac{\left(\ln \left(x / x_{c}\right)\right)^{2}}{2 w^{2}}\right)
$$

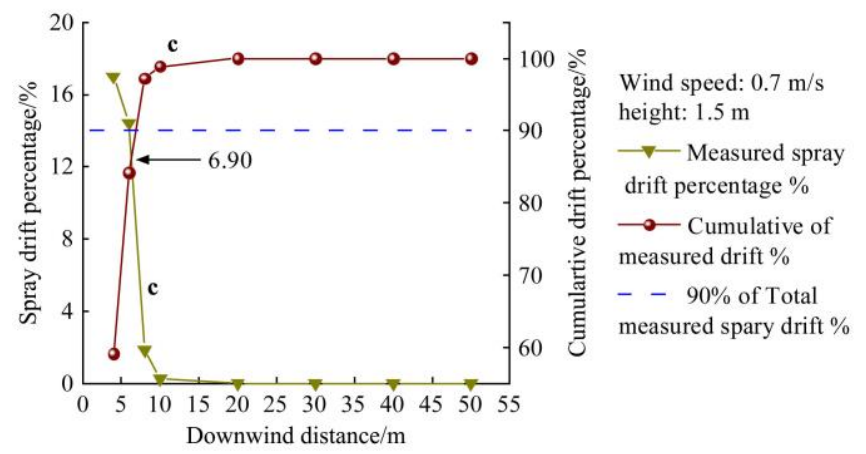

Figure 8 c-curve In-swath and downwind from edge of swath deposit as measured on horizontal mylar cards

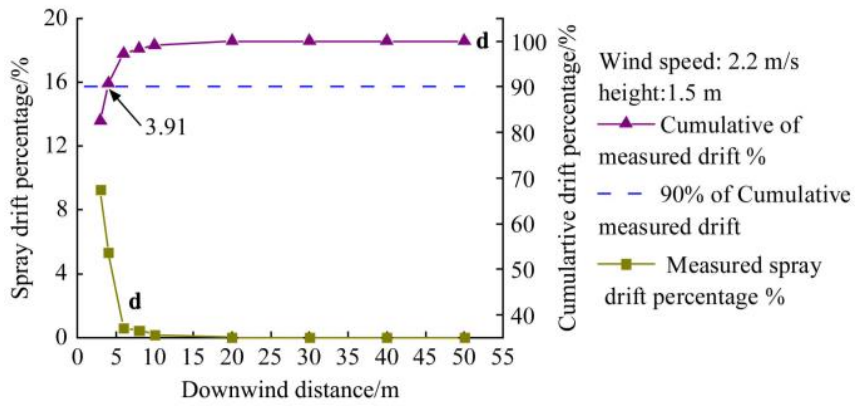

Figure 9 d-curve in-swath and downwind from edge of swath deposit as measured on horizontal mylar cards

Table 4 c and d Curves drift nonlinear fitting curve coefficients

\begin{tabular}{ccccc}
\hline & $Y_{0}$ & $A$ & $w$ & $X c$ \\
\hline $\mathbf{c}$ & $4.75863 \mathrm{E}-5$ & 0.11813 & 0.22748 & 5.0522 \\
$\mathbf{b}$ & $1.89224 \mathrm{E}-4$ & 0.04995 & 0.31746 & 3.14676 \\
\hline
\end{tabular}

Figures 10 and 11 show $\mathbf{e}$ and $\mathbf{f}$-curves in the downwind of spray drift percentage and the cumulative drift percentage of total measuring drift at each sampling point. At the UAV operating height of $3.5 \mathrm{~m}$, real-time wind speeds were $3.7 \mathrm{~m} / \mathrm{s}$ and $1.78 \mathrm{~m} / \mathrm{s}$ with same wind direction. The e-curve shows the cumulative drift percentage of $90 \%$ total measuring drift occurred at about $46.50 \mathrm{~m}$, and the spray drift percentage was $17.80 \%$ at the $10 \mathrm{~m}, 0.08 \%$ at $20 \mathrm{~m}$, and $3.71 \%$ at $30 \mathrm{~m}$, drift spray percentage increased to $29.53 \%$ at the $40 \mathrm{~m}$ position, decreased to $0.25 \%$ at $50 \mathrm{~m}$, and decreased to zero in upwind. The e-curve in-swath area moved to 2-8 $\mathrm{m}$. The e-curve total spray drift accounted for $55.76 \%$ of the total spraying. The e-curve shows that the cumulative drift percentage of $90 \%$ total measuring drift occurred at about $33.54 \mathrm{~m}$. After $3 \mathrm{~m}$, drift was almost stable, and no more than $3 \%$, except for at the $10 \mathrm{~m}$ position with spray drift percentage of $4.29 \%$. The f-curve shows that the total amount of drift accounted for $33.33 \%$ of the total amount of spraying. The change of wind speed at the (2-8) $\mathrm{m}$ position had significant effect on the deposition of $\mathbf{e}$ and $\mathbf{f}$ $(p<0.05)$-curves. The drift curves need to be segmented and the data were not sufficient enough for fitting.

Figure 12 shows a-e curves in the whole sample line of spray drift percentage. Table 5 shows the a-e curves spray drift percentage parameters. As it can be seen from Figure 12 and Table 5, the $90 \%$ of the total measured spray drift position varied from $3.91 \mathrm{~m}$ to $46.50 \mathrm{~m}$. When the UAV operation height was lower than $2.5 \mathrm{~m}$, the mean speed $(\mathrm{SD}<0.76, \mathrm{CV}<0.27)$ was less than $2.82 \mathrm{~m} / \mathrm{s}$, we could control the $90 \%$ of the total measured spray drift position within $10 \mathrm{~m}$. At the UAV operation height of $3.5 \mathrm{~m}$, the mean speed $(\mathrm{SD}<0.73, \mathrm{CV}<0.20)$ was less than $3.93 \mathrm{~m} / \mathrm{s}$, and the position of $90 \%$ of the total measured spray drift can up to $46.50 \mathrm{~m}$. The droplets drift distribution was chaotic that should be paid much more attention in UAV spray application.

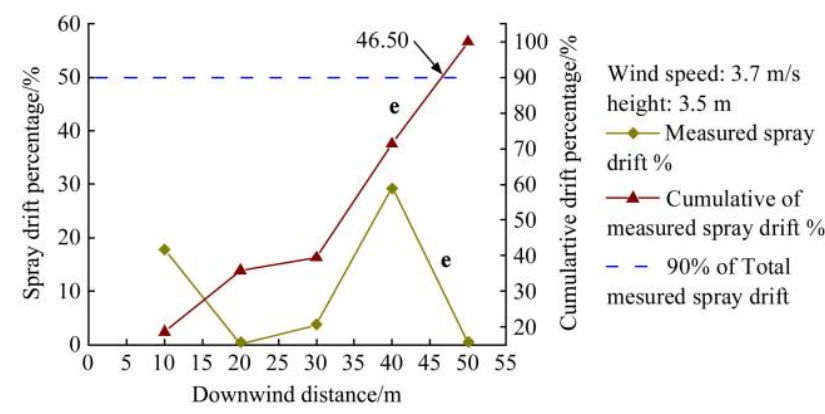

Figure 10 e-curve in-swath and downwind from edge of swath deposit as measured on horizontal mylar cards 


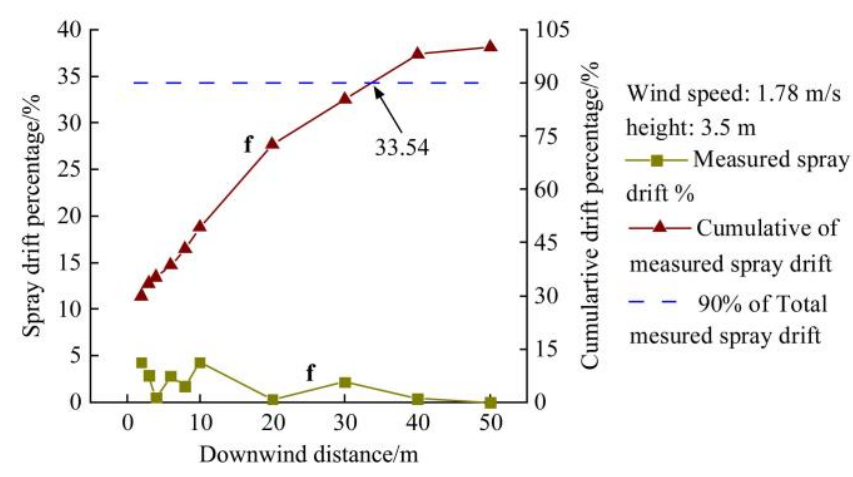

Figure 11 f-curve in-swath and downwind from edge of swath deposit as measured on horizontal mylar cards

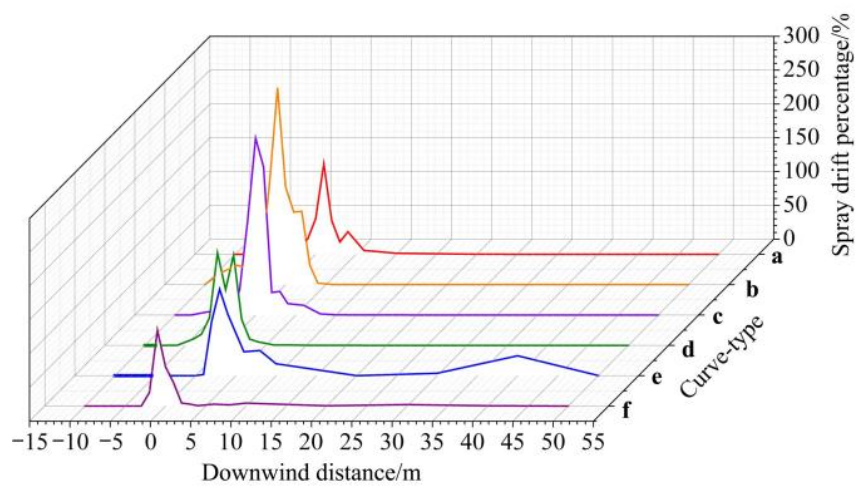

Figure 12 a-e curves in-swath and downwind from edge of swath spray drift percentage as measured on horizontal mylar cards

Table 5 a-e curves spray drift percentage parameters

\begin{tabular}{ccccccc}
\hline Parameter & a & b & c & d & e & f \\
\hline $90 \%$ Drift/m & 10.05 & 3.70 & 6.90 & 3.91 & 46.50 & 33.54 \\
Total drift/\% & 26.44 & 23.20 & 15.42 & 18.82 & 55.70 & 33.33 \\
\hline
\end{tabular}

These results were similar to that from Fritz ${ }^{[26]}$, it indicated increased downwind ground deposition resulting from increased wind speed, the results indicated that wind speed was the most dominant meteorological factor in the transport and fate of aerially applied sprays.
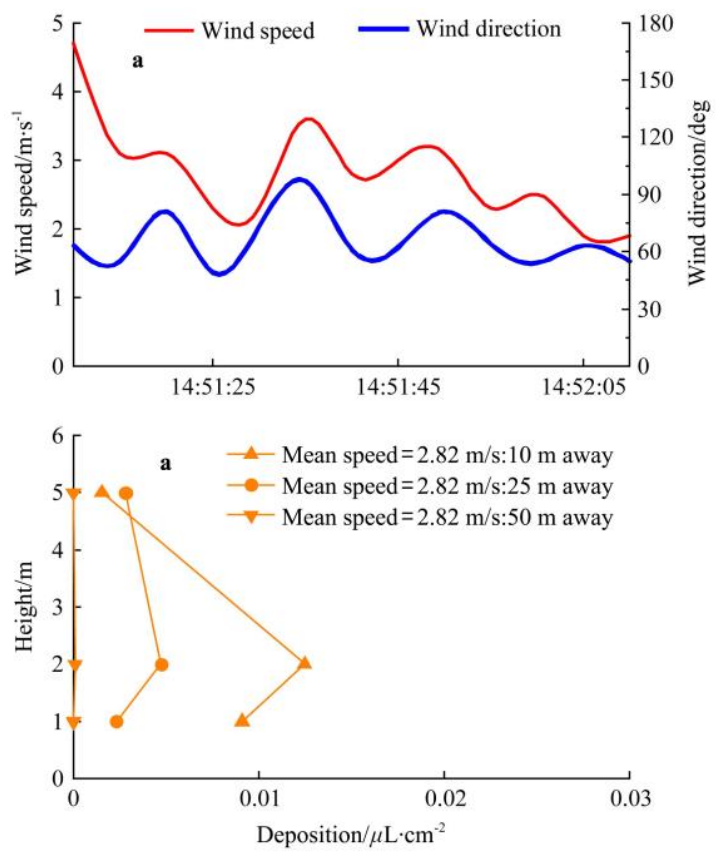

3.3 Monofilament lines samplers at $10 \mathrm{~m}, 25 \mathrm{~m}$, and $50 \mathrm{~m}$ vertical string tests under different meteorological conditions

Drift testing devices were arranged at $10 \mathrm{~m}, 25 \mathrm{~m}$, and $50 \mathrm{~m}$ paralleled to the flight line. Each drift testing device had 3 monofilament lines at the heights of $5 \mathrm{~m}, 2 \mathrm{~m}$, and $1 \mathrm{~m}$. The meteorological chart records the average meteorological data for UAV within $60 \mathrm{~s}$ from the start of the operation. Table 6 shows the a-e curves spray drift meteorological data in $60 \mathrm{~s}$. It shows the standard deviation and coefficient of variation for each curve in $60 \mathrm{~s}$ with the wind speed and wind direction. As shown in Figure 13 , at the UAV operating height of $2.5 \mathrm{~m}$, b-curve monofilament lines deposition was relative to a-curve at $10 \mathrm{~m}$ position. The deposition rates of single monofilament decreased $90.70 \%, 97.16 \%$ and $97.67 \%$ at the testing device height of $5 \mathrm{~m}, 2 \mathrm{~m}$, and $1 \mathrm{~m}$, respectively. At $5 \mathrm{~m}, 2 \mathrm{~m}$ and $1 \mathrm{~m}$ height of the drift testing device, the b-curve drift deposition was almost 0 at the $25 \mathrm{~m}$ position. At the $50 \mathrm{~m}$ position, both $\mathbf{a}$ and $\mathbf{b}$-curves were nearly 0 . The a-curve had a wind speed of $4.7 \mathrm{~m} / \mathrm{s}$ at the moment of spraying, and the drift deposit and drift distance were significantly increased than b-curve.

In Figure 14, c-curve and d-curve had the similar meteorological condition. At the height of $1.5 \mathrm{~m}$ of UAV operating, c-curve drift deposition was almost 0 at all the drift testing devices located at $10 \mathrm{~m}, 25 \mathrm{~m}$ and $50 \mathrm{~m}$. At $10 \mathrm{~m}$ position, the d-curve monofilament lines deposition was very low and no more than $0.00046 \mu \mathrm{L} / \mathrm{cm}^{2}$ at the heights of $5 \mathrm{~m}, 2 \mathrm{~m}$ and $1 \mathrm{~m}$. The d-curve spray drift were almost 0 at $25 \mathrm{~m}$ and $50 \mathrm{~m}$ locations. Although c-curve had a lower wind speed than b-curve at the moment of spraying, the mean speed was not much difference. The d-curve spray drift deposit and distance were not significantly increased compare to c-curve. In Figure 15, e-curve and f-curve were measured at the height of $1.5 \mathrm{~m}$ of UAV operating. The $\mathbf{f}$-curve drift testing devices located at $5 \mathrm{~m}, 25 \mathrm{~m}$ and $50 \mathrm{~m}$. At the $25 \mathrm{~m}$ position, the mean speed was $2.02 \mathrm{~m} / \mathrm{s}$ for $\mathbf{f}$-curve and $3.59 \mathrm{~m} / \mathrm{s}$ for e-curve. The deposition rate of f-curve decreased $75.77 \%$, $85.47 \%$ and $70.18 \%$, relative to the e-curve at the monofilament lines height of $5 \mathrm{~m}, 2 \mathrm{~m}$ and $1 \mathrm{~m}$, respectively. The drift deposition of e-curve was considerably high at $25 \mathrm{~m}$, up to $0.0149 \mu \mathrm{L} / \mathrm{cm}^{2}$.
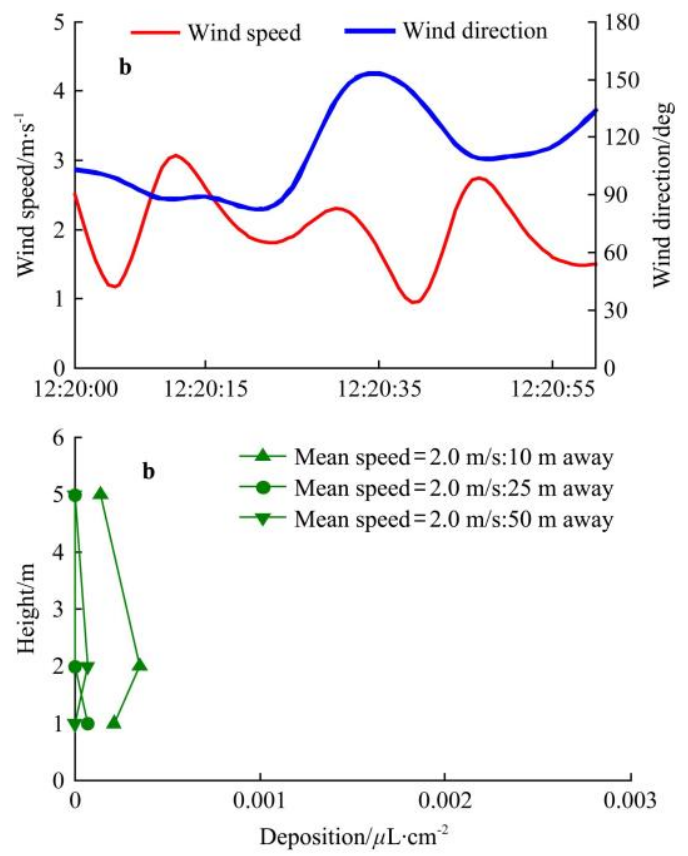

Figure $13 \mathbf{a}$ and $\mathbf{b}$ curves deposition by treatment on monofilament lines placed $10 \mathrm{~m}, 25 \mathrm{~m}$, and $50 \mathrm{~m}$ downwind from the swath edge at three testing device heights $(1 \mathrm{~m}, 2 \mathrm{~m}$, and $5 \mathrm{~m})$ 

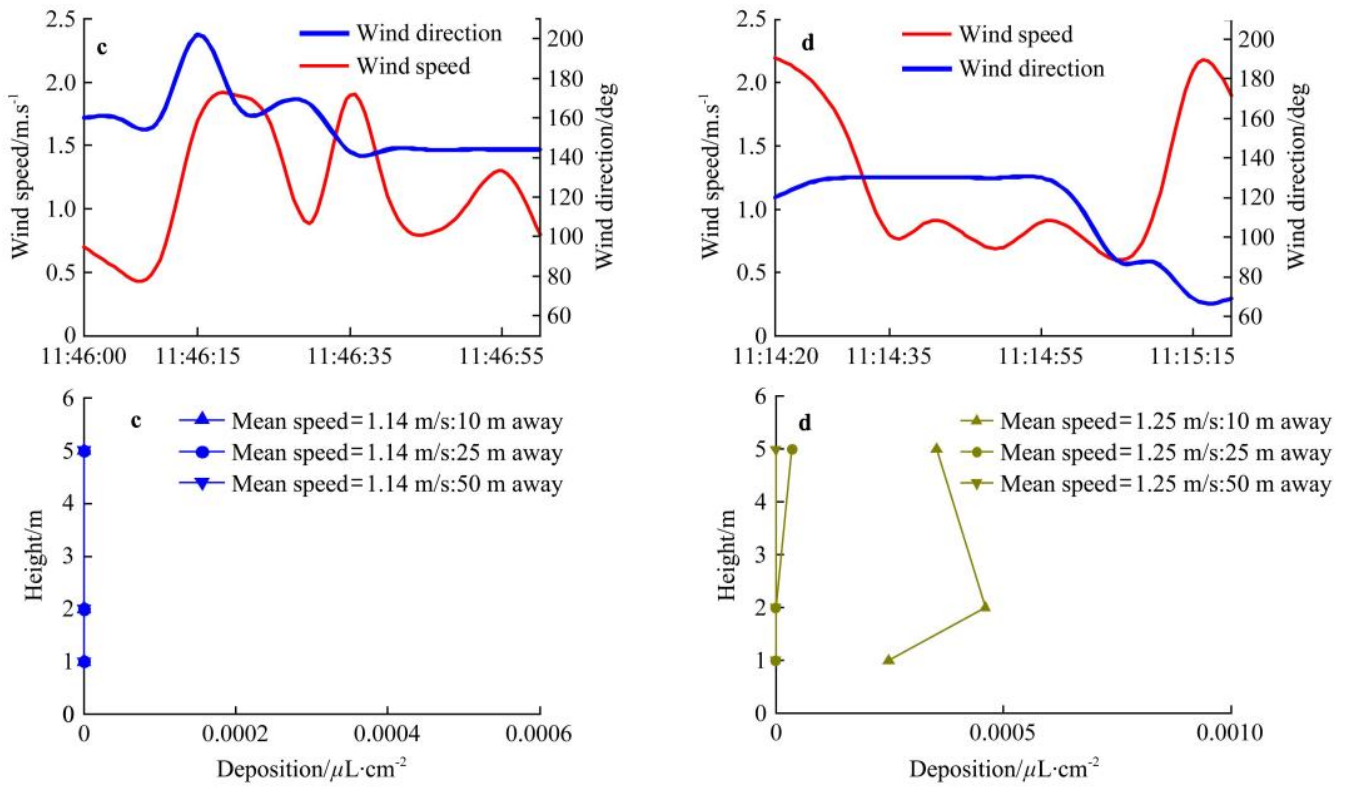

Figure $14 \mathbf{c}$ and $\mathbf{d}$ curves deposition by treatment on monofilament lines placed $10 \mathrm{~m}, 25 \mathrm{~m}$, and $50 \mathrm{~m}$ downwind from the swath edge at three heights $(1 \mathrm{~m}, 2 \mathrm{~m}$, and $5 \mathrm{~m})$
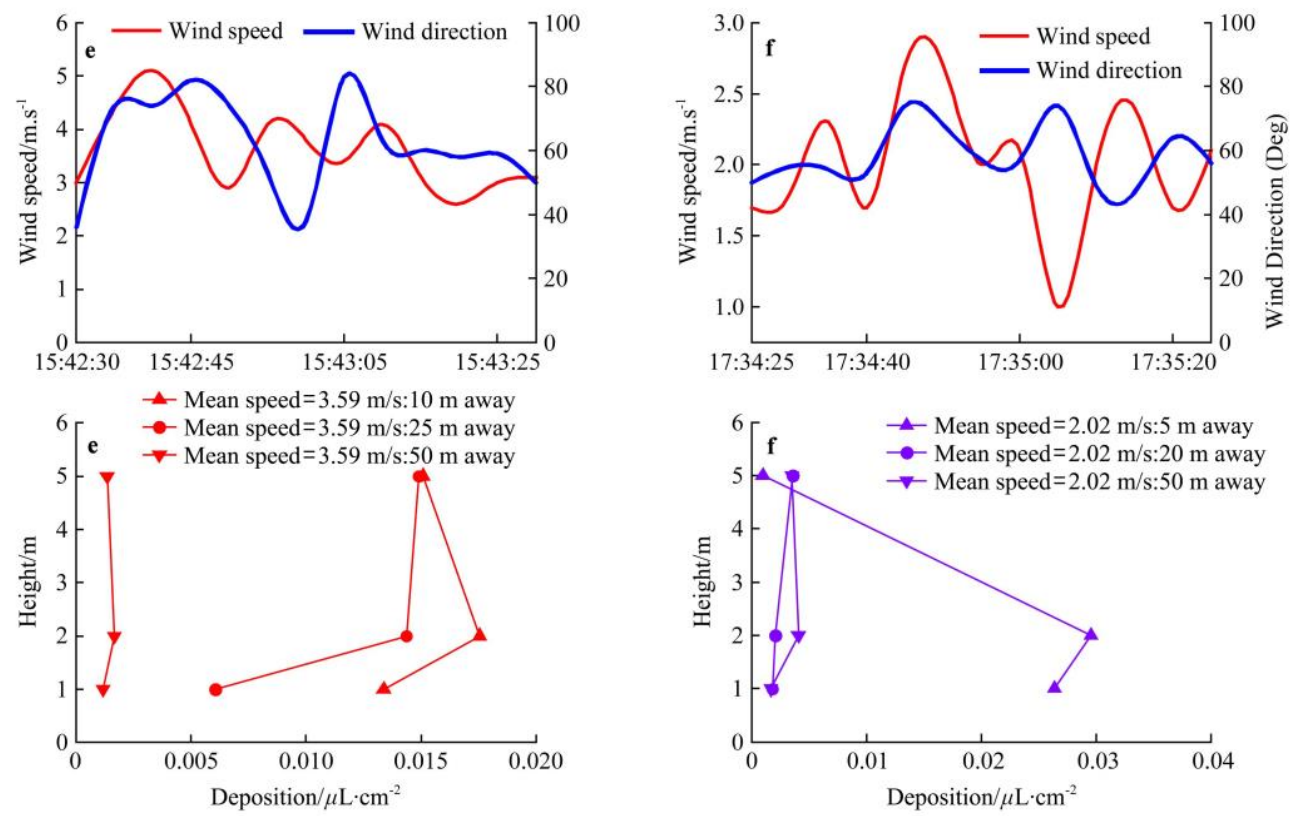

Figure 15 e and $\mathbf{f}$ curves deposition by treatment on monofilament lines placed $10 \mathrm{~m}, 25 \mathrm{~m}, 50 \mathrm{~m}$ downwind from the swath edge at three heights $(1 \mathrm{~m}, 2 \mathrm{~m}$, and $5 \mathrm{~m})$

At $50 \mathrm{~m}$, both $\mathbf{e}$ and $\mathbf{f}$ curves had spray drift deposition. At $5 \mathrm{~m}$ and $2 \mathrm{~m}$ monofilament line heights, f-curve deposition was three times of those in the e-curve. At $1 \mathrm{~m}$ height, the amount of deposition was similar. When the operating height of the UAV increased to $3.5 \mathrm{~m}$, the wind speed ranged at $2.1-4.1 \mathrm{~m} / \mathrm{s}$, and wind direction was $55^{\circ}$. The droplets were likely to drift more than $50 \mathrm{~m}$. The spray deposition of the lower mean wind speed can drift more seriously at some location because of the unstable wind speed during the UAV operation. Again, it showed that increased airborne concentrations resulting from smaller droplet sprays and increased wind speed. Airborne concentration data demonstrated that increased atmospheric stability increased the time that smaller droplets remained suspended in the air, which could lead to increased downwind transport ${ }^{[26]}$.

\section{Conclusions}

With the increase of the mean wind speed and UAV operating height, spray drift distance and the total spray drift percentage also increased rapidly. When the average wind speed is less than $3 \mathrm{~m} / \mathrm{s}$, the flying height of the UAV is preferably controlled to be less than $2.5 \mathrm{~m}$, which can effectively control the spray drift. The influence of the UAV operation height on the total spray drift percentage was significant. When the operation height was less than $2.5 \mathrm{~m}$ and the mean speed varied in $1.14-2.82 \mathrm{~m} / \mathrm{s}$, the total spray drift percentage just floated $11 \%$ and was less than $26.44 \%$. As the UAV operation height was up to $3.5 \mathrm{~m}$, the mean speed varied in $2.02-3.59 \mathrm{~m} / \mathrm{s}$, and the total spray drift percentage reached $55.76 \%$. The influence of the UAV operation height and wind speed on the position of cumulative spray drift percentage of $90 \%$ of the total measured spray drift were significant. The position varied in 3.91-46.50 m. When the operation height was less than $2.5 \mathrm{~m}$, the mean speed varied in $1.14-2.82 \mathrm{~m} / \mathrm{s}$, and the $90 \%$ spray drift distance can control in $10 \mathrm{~m}$. As the operation height was up to $3.5 \mathrm{~m}$, the mean speed varied in $2.02-3.59 \mathrm{~m} / \mathrm{s}$, and the $90 \%$ 
spray drift distance can be up to $33.54-46.50 \mathrm{~m}$.

With the increase of the real time wind speed and UAV operating height, the in-swath area and spray deposition changed obviously. The influence of the wind speed on the distribution of the in-swath area was obvious when the UAV operating height was not lower than $2.5 \mathrm{~m}$. The in-swath area start position moved 3$4 \mathrm{~m}$ as the wind speed changed, especially when the real time wind speed changed greatly. The wind speed had a statistically significant $(p<0.05)$ effect on the in-swath area deposition.

With the increase of the wind speed and UAV operating height, the influences of the wind speed and UAV operating height on the monofilament lines deposition of drift testing devices were significant. At the $1.5 \mathrm{~m} \mathrm{UAV}$ operating height, the wind speed varied in $0.5-2.2 \mathrm{~m} / \mathrm{s}$, and all the monofilament lines deposition were nearly 0 . At the $2.5 \mathrm{~m}$ UAV operating height, the wind speed varied in 1.0-4.7 m/s, and the monofilament lines deposition had obviously changes as the wind speed changed. At the $3.5 \mathrm{~m}$ UAV operating height, the wind speed varied in $1.0-5.1 \mathrm{~m} / \mathrm{s}$, and the monofilament lines deposition were considerably high.

In actual operation, UAV operating height should below $2.5 \mathrm{~m}$ when spraying in pineapple plants and the wind speed should be $5 \mathrm{~m} / \mathrm{s}$ or less. If UAV needs a higher height, we should choose a smaller wind speed and stable weather condition and set enough buffer zone.

In this research, pesticide applied by UAV test was carried out based on real-time meteorology. The experiment proved that the wind speed had a significant effect on the spraying efficacy. The UAV operation parameters should be reasonably selected according to the meteorological conditions. When in-swath area offset occurs due to meteorological conditions, remedial measures should be taken to prevent reinjection and leakage.

\section{Acknowledgments}

We acknowledge that this work was financially supported by the National Key Technologies Research and Development Program (2016YFD0200700), Guangdong Leading Talent Project (2016LJ06G689), 111 Project (D18019), Educational Commission of Guangdong Province of China for Platform Construction (2015KGJHZ007), and Science and Technology Planning Project of Guangdong (2017B010117010). Thanks to the National Center for International Collaboration Research on Precision Agricultural Aviation Pesticides Spraying Technology for the full participation persons of the experiment (Weixiang Yao, Pengchao Chen, Changquan Yue, Xiaoyu Huang, Jinli Lin, Linlin Wang, Changwei Zhu, Yusen Deng, Cong Huang, Yulong Fu). Thanks to Hainan NongFeiKe Agriculture and Technology Co., Ltd. for their fully support.

\section{[References]}

[1] Kirk I W. Aerial spray drift from different formulations of glyphosate. Transactions of the ASABE, 2000; 43(3): 555-559.

[2] Ru Y, Zhou H P, Jia Z C, Wu X W, Fan Q N. Design and application of electrostatic spraying system. Journal of Nanjing Forestry University: Natural Science Edition, 2011; 35(1): 91-94. (in Chinese)

[3] Huang Y, Hoffmann W C, Lan Y, Wu W, Fritz B K. Development of a spray system for an unmanned aerial vehicle platform. Transactions of the ASABE, 2009; 25(6): 803-809.

[4] Zhang W, Hou Y R, Liu X, Lian Q, Fu X M, Zhang B, et al. Wind tunnel experimental study on droplet drift reduction by a conical electrostatic nozzle for pesticide spraying. Int J Agric \& Biol Eng, 2017; 10(3): 87-94.

[5] Otto S, Loddo D, Baldoin C. Spray drift reduction techniques for vineyards in fragmented landscapes. Journal of Environmental
Management, 2015; 162(2): 290-298.

[6] Pankaj G, Sirohi N P S, Mishra I M. Air flow characteristics of an air-assisted sprayer through horizontal crop canopy. Int J Agric \& Biol Eng, 2012; 5(1): 1-6.

[7] Qin W C, Xue X Y, Cui L F, Zhou Q Q, Xu Z F, Chang F L. Optimization and test for spraying parameters of cotton defoliant sprayer. Int J Agric \& Biol Eng, 2016; 9(4): 63-72.

[8] Gil E, Balsari P, Gallart M. Determination of drift potential of different flat fan nozzles on a boom sprayer using a test bench. Crop Protection, 2014; 56(2): 58-68.

[9] Dodge T. New spray technology driven by drift. American Farm Industry News, 1998; March 1. Available online: http://www.farmindustrynews.com/new-spray-technology-driven-drift.

[10] Nigar Y B. Assessment of buffer zone for aquatic organisms in pesticide application. Int J Agric \& Biol Eng, 2016; 9(5): 227-234.

[11] Sudheer K P, Panda R K. Digital image processing for determining drop sizes from irrigation spray nozzles. Agricultural Water Management, 2000; 45(2): 159-167.

[12] Panneton B, Philion H, Theriault R, Khelifi M. Spray chamber evaluation of air-assisted spraying on potato plants. Transactions of the ASAE, 2000 43(3): 529-534.

[13] Law S E. Agricultural electrostatic spray application: a review of significant research and development during the 20th century. Journal of Electrostatics, 2001; 51(1): 25-42.

[14] Yang X J, Yan H R, Xu S Z, Liu Z. Current situation and development trend of equipment for crop protection. Transactions of the CSAM, 2002; 33(6): 129-137. (in Chinese)

[15] Smith D B, Bode L E, Gerard P D. Predicting ground boom spray drift. Transactions of the ASABE, 2000; 43(3): 547-553.

[16] He X K, Zeng A J, He J. Effect of wind velocity from orchard sprayer on droplet deposit and distribution. Transactions of the CSAE, 2002; 18(4): 75-78. (in Chinese)

[17] Liu X J, Zhou H P, Zheng J Q. Research advances of the technologies for spray drift control of pesticide application. Transactions of the CSAE, 2005; 21(1):186-190. (in Chinese)

[18] Whitney J D, Salyani M, Churchill D B, Knapp J L, Whiteside J O, Little R C. A field investigation to examine the effects of the sprayer type, ground speed, and volume rate on spray deposition in Florida citrus. Journal of Agricultural Engineering Research, 1989; 42: 275-283.

[19] Hewitt A J, Katan J, Aharonson N, Cohen E, Rubin B. Spray drift: impact of requirements to protect the environment. Crop Protection, 2000 19: 623-627.

[20] Vol N. Spraying technologies for cotton deposition and efficacy. Applied Engineering in Agriculture, 1996; 13(3): 287-296.

[21] van de Zande J C, Huijsmans J F M, Porskamp H A J, Michielsen J M G P, Stallinga H, Holterman H. Spray techniques: how to optimize spray deposition and minimize spray drift. Environmentalist, 2008; 28: 9-17.

[22] Hoffmann W C, Hewitt A J. Comparison of three imaging systems for water-sensitive papers. 2004; ASAE Annual Meeting, No: 041030.

[23] Franz E, Bouse L F, Carlton J B, Kirk I W, Latheef M A. Aerial spray deposit relations with plant canopy and weather parameters. Transactions of the ASAE, 1998; 41(4): 959-966.

[24] Lan Y, Hoffmann W C, Fritz B K, Martin D E, Lopez J D. Spray drift mitigation with spray mix adjuvants. Applied Engineering in Agriculture, 2008; 24(1): 5-10.

[25] Xue X Y, Tu K, Qin W C, Lan Y B, Zhang H H. Drift and deposition of ultra-low altitude and low volume application in paddy field. Int $\mathrm{J}$ Agric \& Biol Eng, 2014; 7(4): 23-28.

[26] Fritz B K. Meteorological effects on deposition and drift of aerially applied sprays. Transactions of the ASABE, 2006; 49(5): 1295-1301.

[27] Shi W Q, Sun W S, Xi J E, Chen J, Zuo D Q. China pineapple industry status and development countermeasures. Guangdong Agricultural Sciences, 2011; 3: 181-185. (in Chinese)

[28] Chen S D, Lan Y B, Li J Y, Zhou Z Y, Liu A M, Mao Y D. Effect of wind field below unmanned helicopter on droplet deposition distribution of aerial spraying. Int J Agric \& Biol Eng, 2017; 10(3): 67-77.

[29] Lan Y B, Chen S D, Li J Y, Zhang Y L, Huang C, Yao W X, et al. Evaluation system of flying flight quality based on Beidou locating system. Chinese Patent, CN205563277U, 2016-09-07. (in Chinese)

[30] Bird S L, Esterly D M, Perry S G. Off-target deposition of pesticides from agricultural aerial spray applications. Journal of Environmental Quality, 1996; 25(5): 1095-1104. 